\title{
Los fines de la historia en el siglo XXI
}

Carlos Barros $^{I I}$

Resumen: Superado el debate sobre el "fin de la historia", cuya continuidad post-1989 está fuera de duda, estamos con el nuevo siglo en el debate sobre los "fines de la historia". Entendemos "fines" como los objetivos que, en el inicio del siglo XXI, están perfilando prácticamente en el ámbito global los nuevos y viejos sujetos sociales, económicos y políticos. Hemos identificado cinco fines en marcha: mercado global, califato islámico, socialismo del siglo XXI, autoritarismo de Estado y Gobierno Mundial democrático, que analizamos en detalle aplicando el criterio historiográfico pasado/presente/futuro (Historia Inmediata).

Palabras clave: Historia, globalización, presente, futuro, fin.

\section{The ends of history in the 21 st century}

\begin{abstract}
Having overcome the debate on the "end of history", whose post-1989 continuity is beyond doubt, we are with the new century in the debate on the "ends of history". We understand "ends" as the objectives that at the beginning of the 21st century are practically shaping the new and old social, economic and political subjects in the global sphere. We have identified five purposes in progress: Global Market, Islamic Caliphate, Socialism of the 21st century, Authoritarianism of the State and Democratic World Government, which we analyze in detail applying the past / present / future historiographical criterion (Immediate History).
\end{abstract}

Keywords: History, Globalization, Present, Future, End.

Artigo recebido em 14/11/2017 e aprovado em 03/12/2017.

Cadernos do Tempo Presente, São Cristóvão-SE, v. 08, n. 04, p. 03-15, jul./dez. 2017| http://www.seer.ufs.br/index.php/tempo 
En esta ocasión no entendemos por "fines de la historia" las terminaciones de la historia al modo filosófico de Hegel, Marx y otros ${ }^{\mathrm{III}}$ sino los objetivos históricos que partes de la humanidad van construyendo y expresando en este nuevo siglo de una manera más o menos explícita. Se trata por tanto de fines en marcha, reales, que conllevan a menudo representaciones imaginarias que movilizan a sectores amplios de la sociedad. Vamos pues a definir y analizar ${ }^{\mathrm{IV}}$ en este siglo XXI fines de la historia ya existentes, a las puertas de la tercera década, sostenidos -o impuestos- por fuerzas económicas, políticas, sociales o religiosas en ámbitos internacionales, con la ventaja de la inmediatez ${ }^{\mathrm{V}}$ : el hecho de que se estén dando y los estemos viviendo, de que no sean por consiguiente simples opciones o proyectos $^{\mathrm{VI}}$, facilita nuestra perspectiva pasado/presente/futuro.

Partimos del punto XIV del Manifiesto historiográfico de Historia a Debate dado a conocer el 11 de setiembre de 2001, donde decíamos que "la aceleración histórica en la última década ha reemplazado el debate sobre el 'fin de la historia' por el debate sobre los 'fines de la historia'. Asumiendo que la historia no tiene metas preestablecidas y que, en 1989, dio comienzo un profundo viraje histórico... El futuro está abierto"VII, concluíamos.

Estamos inmersos en una sorpresiva transición entre el siglo XX y el siglo XXI, si consideramos las falsas e interesadas previsiones sobre el "final de la historia", que ha generado (causa y consecuencia) una inacabada globalización tan arrolladora como desigual, social y espacialmente, con unos efectos secundarios que recuerdan aquello que decía Marx de que el capitalismo engendra su enterrador... La extensión de la democracia -y la conclusión de la política de bloques- ha puesto término a los golpes cruentos y las dictaduras declaradas, haciendo posible, no es poco para la "democracia burguesa", la llegada al poder paradoja y pacíficamente de la izquierda revolucionaria y socialista en parte de América Latina.

La mundialización rampante no afecta solamente al comercio, la industria y las finanzas, también a las comunicaciones, los grandes valores y los movimientos sociales, que actúan de contrapunto del poder omnímodo del dinero global y las multinacionales. El motor de esta transición acelerada al nuevo siglo es una revolución científico-técnica desconocida en la evolución humana, a la vez digital y biológica, que está lejos de haber alcanzado su cenit y afecta a todos los ámbitos de la vida y de la tierra. La informática, la automatización y la nanotecnología, el monstruo de Internet, la inteligencia artificial y los espectaculares adelantos en medicina están alargando espectacularmente la esperanza de la vida humana: un mundo nuevo.

Mas los beneficios no son para todos, hoy por hoy, ni siquiera en las regiones del planeta más favorecidas por la globalización en curso, salvo que la sociedad y la política logren controlar democráticamente el nuevo siglo global y asegurar su sostenibilidad (crecimiento económico, justicia social, paz y respeto al medio ambiente), sorteando la distopía. Partiendo claro está de los nuevos sujetos que están surgiendo de la caída de los fines de la historia del siglo XX y la disolución de las dictaduras, los bloques y los imperios.

Pasadas dos décadas del siglo XXI hallamos sobre el tapete cinco fines relativos a la organización de la sociedad, la política y la economía en este mundo globalizado, con diferentes grados de realización, protagonismo, novedad y amplitud internacional. Según orden de aparición: 1) Mercado global. 2) Califato islámico. 3) Socialismo del siglo XXI. 4) Autoritarismo de Estado. 5) Gobierno mundial de conformación

Cadernos do Tempo Presente, São Cristóvão-SE, v. 08, n. 04, p. 03-15, jul./dez. 2017| http://www.seer.ufs.br/index.php/tempo 


\title{
LOS FINES DE LA HISTORIA EN EL SIGLO XXI
}

\author{
CARLOS BARROS
}

democrática, el más proyectivo e imperioso desde una idea actualizada de progreso, en nuestra opinión. A diferencia del pasado siglo ${ }^{\mathrm{VIII}}$, los conflictos entre estos fines divergentes de la historia tienen ahora una resolución no-violenta, democrática en el sentido más amplio del concepto, a excepción del terrorismo global.

\section{Mercado global}

El mercado global, o la globalidad entendida como un gran mercado, es hoy por hoy lo realmente existente. Impuesto por los nuevos sujetos económicos favorecidos por los espectaculares avances tecnológicos, y sus aplicaciones globales, la mundialización gira en lo económico alrededor del libre comercio (decimonónico de origen), y pretenden que la política, la sociedad y la cultura pivoten de la misma forma en torno al laissez faire. Detrás está un conglomerado transnacional de grandes empresas donde lo decisivo es el mundo de las finanzas, en su dimensión más especulativa y avariciosa, desconectada peligrosamente tanto de la economía real, productiva, como de las necesidades y los derechos humanos y democráticos del común de los mortales. Intereses macroeconómicos que no están sujetos, como es sabido, a ningún tipo eficaz de control político y democrático, más bien lo contrario: el desgobierno global de la economía es el mayor e inquietante déficit democrático que sufre el mundo en lo que llevamos recorrido del siglo XXI.

Esta antinomia entre el poder económico (de ámbito internacional) y el poder político (de ámbito nacional) ha dado lugar a la llamada "gobernanza" iX internacional interesadamente débil y disgregada, lenta e ineficaz, subyugada por el laissez faire y tendente por esta razón a la desvalorización del sector público. El resultado es el llamado Nuevo Orden Mundial, criticado justamente como un Desorden Mundial, al estar troceado en múltiples organizaciones sin una institución superior, legitimada democráticamente, que oriente, gobierne y coordine.

Tipos de organizaciones-parches para la gobernanza internacional en el nuevo siglo: 1) La Organización de las Naciones Unidas, el Fondo Monetario Internacional y el Banco Mundial, nacidas después de la II Guerra Mundial y reutilizadas en la era de la globalización para "gestionar" la nueva economía y la seguridad, así como las posteriores Organización para la Cooperación y el Desarrollo Económicos (1961) y Organización Mundial de Comercio (1995). 2) Los grupos informales de países más desarrollados G7 (1973) y G20 (1999), que coordinan decisiones económicas y de otro tipo, que afectan al mundo entero. 3) Foros de dirigentes de instituciones internacionales, financieros, empresarios, políticos e intelectuales que buscan influir en el devenir de la globalización, como el privado Foro Económico Mundial ${ }^{\mathrm{X}}$ que se reúne todos los años en Davos (Suiza) y el Grupo Bildelberg (hotel holandés donde se reunió por vez primera), más exclusivo, menos numeroso y para nada transparente, fundado durante la guerra fría (1954) a iniciativa de los EE.UU.; se siguen reuniendo anualmente para asegurar y mejorar el establishment mundial, desde el punto de vista ante todo del conglomerado financiero e industrial que domina la economía global siempre reacio a un control público de sus intereses y actividades, sin que ello quiera decir que se cuelen opiniones reformistas, sobre todo después del crac de 2008.

Este monumental reino de taifas de la gobernanza internacional ni quiere ni puede controlar el devenir de un mundo marcado por las nuevas revoluciones de la ciencia y la comunicación, por un lado, y unos mercados financieros desregulados (en

Cadernos do Tempo Presente, São Cristóvão-SE, v. 08, n. 04, p. 03-15, jul./dez. 2017| http://www.seer.ufs.br/index.php/tempo 
ocasiones, enloquecidos), por el otro. Procesos que provocan tanto beneficios como perjuicios que se agravan y agrandan conforme nos adentramos en el siglo. Verbigracia, una desigualdad social, económica y geopolítica que se acrecienta: el $75 \%$ del PIB mundial está ahora en Occidente. China y los BRICS constituyen para algunos un contrapeso esperanzador, pero no suponen desde luego una alternativa ${ }^{\mathrm{XI}}$ a Occidente más democrática para un mundo más humano y ecológico. Mientras tanto, la generación joven sigue sin futuro y el África subsahariana sufre ya crisis alimentaria, hambre, pandemia y pobreza, que se irán expandiendo a otras zonas pobres del planeta si no hay pronto un cambio real de rumbo en la política mundial.

La mejor prueba de carácter caótico, desordenado, en interés de unos pocos, del mercado global, es la crisis económica del año 2008 provocada por el capital financiero, emparentable a lo que fue la crisis de 1929 y seguida de una Gran Recesión que dura una década interminable (para sus víctimas, que somos casi todos), semejante a la que en los años 30 causó el ascenso del nazifascismo, lo que por fortuna no está pasando en el siglo XXI, al juntarse en las mentalidades colectivas de manera indisoluble las aspiraciones de más justicia social y más democracia real.

Esta primera gran crisis de la economía del siglo XXI, coadyuvada por una endeble, segmentada y subalterna gobernanza global (respecto del conglomerado económico multinacional), ha generado dos tipos de reacciones que pueden agrandarse en el próximo futuro, además de la crisis irreversible del neoliberalismo, antaño "pensamiento único", junto con su correspondiente sistema de poder interesadamente anárquico.

Se ha disparado, en primer lugar, un movimiento social antiglobalización que tuvo sus comienzos en 1999, y evolucionó en Porto Alegre como movimiento altermundista ("Otro mundo es posible"), con un movimiento indignado venido al mundo en $2011^{\mathrm{XII}}$ en respuesta a la crisis del capitalismo global y sus consecuencias. Es probable que en la próxima década tengamos una tercer ola de indignación, protagonizada, como en los dos casos anteriores, por la nueva generación de millenials (nacidos entre 1980 y 2000), coordinados como de costumbre por medio de Internet. Jóvenes del segundo milenio, los más formados de la historia, a los que la sociedad global no ofrece perspectivas de futuro y luchan por "cambiar la historia", como hicimos hace 50 años nuestra generación del 68, en un contexto diferente.

Emerge también con gran fuerza otro movimiento antiglobalización, de tipo político de tinte reaccionario, que ha tenido su máxima expresión en el referéndum en favor del Brexit en Gran Bretaña (2016) y en la victoria de Trump (2017) en Estados Unidos. Se trata de un impetuoso freno institucional a la globalización económica con una amplia base social, en pro del proteccionismo de poderosos Estados-nación Lo que pone fin de manera abrupta e inesperada a la unanimidad de las élites políticoeconómicas del mundo de hoy acerca del mercado libre como máximo regulador de las relaciones internacionales. Respuesta ultraconservadora que refleja, asimismo, la pérdida creciente de hegemonía de los Estados Unidos, y del mundo anglosajón, en la política y la economía mundiales.

La mayor consecuencia política del crac de 2008 ha sido, así y todo, la crisis de irreversible de la democracia representativa -que ya venía dando problemas-, derivada de la deslegitimación de los poderes establecidos y las políticas de austeridad cuya implementación mostró que no somos todos iguales ni social ni geográfica ni generacionalmente a la hora de afrontar la Gran Recesión (muchas grandes empresas

Cadernos do Tempo Presente, São Cristóvão-SE, v. 08, n. 04, p. 03-15, jul./dez. 2017| http://www.seer.ufs.br/index.php/tempo 
vieron incrementarse sus beneficios). El informe del propio Banco Mundial de 2017 relativo a la gobernanza señala el rápido crecimiento, desde la caída del Muro, del número de países que se rigen por constituciones democráticas al tiempo que, paradójicamente, decrecen tanto la participación electoral como la integridad de las elecciones (menos libres y justas) ${ }^{\mathrm{XIII}}$. De ahí el aumento en todo el mundo del desprestigio de los políticos ("son todos iguales"), el malestar contra los poderes fácticos (económicos, mediáticos...) y el alza del sentimiento de injusticia por los privilegios de las élites. Frente a la decadencia de la democracia representativa urge una democracia más incluyente y participativa, más social y global, o bien guerra, regímenes de ultraderecha y la continuidad del caos.

Diez años después de la crisis de 2008, existe cierto consenso entre los especialistas de que se está incubando una nueva crisis económica, puesto que se han tomado medidas globales eficientes que imposibiliten un nuevo desastre originado por un mercado global fuera de control. Las que se tomaron para superar coyunturalmente la crisis de la primera década pueden hacer detonar otra crisis financiera (peor que la de 2008, "escenario de pesadilla", se dice) como consecuencia de una deuda pública y privada imposible de pagar. También se habla de un fuerte incremento del precio del petróleo como motivo crítico de otra crisis, en el marco de la carestía de las energías fósiles y los obstáculos interesados a las energías renovables. La perspectiva de la economía planetaria no es en consecuencia optimista, sigue desbocada: un fin de la historia desesperanzador, si seguimos con una gobernanza internacional limitada, inservible y un mercado global descontrolado.

\section{Califato islámico}

El segundo fin de la historia de transcendencia internacional al que haremos referencia aflora el 11 de setiembre de 2001 y viene del mundo musulmán, oriental y africano. Lo llaman Califato Islámico, es decir, la imposición de la ley islámica o sharía, usando el Corán como Constitución, para gobernar el mundo (Dar-al-Islam, "tierra del Islam") de manera autocrática. Contra la opinión no sólo de los "infieles", también de la mayoría de la población de los países musulmanes. Buscan implantar por la guerra y el terror una visión totalitaria, violenta y sesgada del Corán, aprovechando que el auge de la religión islámica (un 73\% en 2050) y el peso de la corriente salafista.

El islamismo fundamentalista es igualmente un fenómeno paralelo a la globalización, que se agudiza por los efectos funestos de la última crisis en el Este y en Sur, en los países más perjudicados por la mundialización. El terrorismo islámico se nutre de los jóvenes musulmanes sin futuro, y del fracaso de la pacífica y prodemocrática Primavera Árabe, con la excepción de Túnez donde siguen haciendo grandes manifestaciones en enero de 2018, y muchos jóvenes votan para cambiar las cosas.

El impacto global del Califato, tanto en Oriente como en los países occidentales, se explica también por la globalización de las comunicaciones, las intervenciones desafortunadas de Occidente en el Oriente Próximo y por supuesto la inexistencia de un Gobierno Mundial democrático que extienda los beneficios de la globalización a todo el mundo.

Desde 2014 el Estado Islámico (ISIS) ha sustituido a Al-Qaeda centrando sus actividades en la guerra para la conquista de territorio en Irak y Siria ${ }^{\text {XIV }}$, donde se

Cadernos do Tempo Presente, São Cristóvão-SE, v. 08, n. 04, p. 03-15, jul./dez. 2017| http://www.seer.ufs.br/index.php/tempo 


\title{
LOS FINES DE LA HISTORIA EN EL SIGLO XXI
}

\author{
CARLOS BARROS
}

instauró el Califato Islámico en amplias zonas que han ido cayendo frente a los ejércitos de los países afectados con la ayuda de Occidente. Derrota militar que prueba la imposibilidad de estabilizar territorialmente un Califato tiránico contra el resto del mundo, islámico y no islámico.

Este fin integrista de la historia, especialmente represivo para las mujeres, tendrá por el momento continuidad desgraciadamente como terrorismo global contra la población de Occidente y de los los países que abrazan la visión histórica y tolerante del Islam. En cualquier caso, solamente una globalización más igualitaria, que cambie las condiciones de vida de la juventud y las clases populares en los países afectados, podrá resolver definitivamente esta lacra del terrorismo con una base religiosa.

\section{Socialismo del siglo XXI}

Otra respuesta a la globalización desigual, en un contexto de gobiernos de izquierda en América Latina, es el autoproclamado "socialismo del siglo XXI", objetivo de la historia presente en América del Sur a partir de las victorias electorales de Hugo Chávez (1998), seguido después por Evo Morales (2005) en Bolivia y Rafael Correa (2007) en Ecuador, con el sostén de sendos movimientos sociales que dieron paso a nuevas formaciones políticas, todo ello pese a la endeble tradición democrática latinoamericana.

Fin histórico que tiene un interés especial para nosotros por tratarse, en buena parte, de una vuelta insospechada del socialismo de matriz marxista después del desplome del socialismo llamado real en el Este de Europa. Tenía razón Fidel Castro, en 2010, cuando dijo que "el modelo cubano [de impronta soviética] ya no funciona ni siquiera para nosotros"XV . Así pasó en la América bolivariana, donde se intentó alcanzar un Estado social $^{\mathrm{XVI}}$, objetivo compartido históricamente por Estados digamos socialistas gobernados por partidos comunistas y socialdemócratas, no obstante sus diferencias.

Lo nuevo del "socialismo del siglo XXI" sudamericano es el acceso al poder mediante elecciones de fuerzas rupturistas sin golpes militares que lo pudieran frustrar, como sucedió en España en 1936 y en Chile en 1973. Socialismo de origen democrático luego que admite por necesidad la economía de mercado (como una NEP permanente), la globalización y sus consecuencias (como la dependencia en Venezuela del precio del petróleo).

La supervivencia futura de estas experiencias de gobierno, con sus errores y aciertos, y de los movimientos sociopolíticos que han sido su causa y su consecuencia, dependerá de todos modos de la capacidad que tengan para asumir las reglas de la democracia. Pasando a la oposición cuando los resultados les sean adversos ${ }^{\mathrm{XVII}} \mathrm{y}$ defendiendo fuera del poder los logros sociales conseguidos desde el gobierno, que volverían a detentar cuando la voluntad popular les sea de nuevo favorable, siempre que el contexto internacional siga siendo -en Occidente- favorable a una democracia con alternancia donde todos puedan votar y ganar.

\section{Autoritarismo de Estado}

En cuarto lugar, analizaremos otra finalidad de la historia, con más pasado que futuro, la continuidad en el siglo XXI como forma de gobierno de los Estados autoritarios o de tendencia autoritaria. El informe del Centro Nacional de Inteligencia de

Cadernos do Tempo Presente, São Cristóvão-SE, v. 08, n. 04, p. 03-15, jul./dez. 2017| http://www.seer.ufs.br/index.php/tempo 
los EE. UU. en el año de la gran crisis de 2008, Global Trends $2025^{\mathrm{XVIII}}$, pronosticó la decadencia de la democracia en el mundo, comprendiendo Occidente, so pretexto interesado de que los Gobiernos autoritarios iban a estar en mejores condiciones para tomar decisiones económicas globales (neoliberales, se entiende). No ha sido así, tampoco hizo falta. Por otro lado, ni siquiera con Trump en la Casa Blanca los EE. UU. dejan de ser una democracia donde se puede cambiar el Gobierno con los votos, dentro de un orden bipartidista, ciertamente, que está desapareciendo en Europa.

De todas formas, no se puede minusvalorar el hecho de que en países como China, Corea, Turquía, Egipto o Rusia, existan regímenes de partido único o unas democracias formal en la práctica autocráticas y represivas. Son con certeza residuos del pasado, reforzados ahora por el nuevo papel de los viejos Estados nacionales de resistencia a la globalización, en ausencia de una autoridad mundial legítima y efectiva. China y Rusia son además potencias económicas emergentes y forman parte de los BRICS, si bien sus modelos políticos autocráticos son para nada exportables. Tampoco lo intentan, en concreto China, candidata a ser la nueva primera potencia económica a mediados de este siglo. Occidente va claramente, hoy por hoy, en sentido contrario al autoritarismo, ya que la tendencia mayoritaria entre los críticos sociales de la mundialización, "ordenada" por los mercados, pretenden más y mejor democracia, particularmente los jóvenes que también sufren como los que más -muchos luchan contra ello- los efectos nocivos de una globalización desigual que avanza como un pollo sin cabeza.

De cualquier manera, no se puede excluir lo peor en esta tesitura histórica, si la situación se deteriora indefinidamente, fracasan las tentativas de una globalización democrática y las crisis económicas y no económicas alcancen un punto de no-retorno. En fin, muchos somos hijos de la Ilustración, no hay día que no amanezca y mantenemos la esperanza de un futuro más feliz para toda la humanidad, no solamente para unas élites cada vez más restringidas a determinados países.

Por todo lo que venimos escribiendo, hemos inventariado algunas voces significativas, propuestas y prácticas de gobernanza en favor de una globalización con rostro humano que pasa, ineludiblemente, por la articulación política de una soberanía global fundamentada en la democracia representativa y directa.

\section{Gobierno mundial democrático}

Y así llegamos a la quinta meta histórica, remate y conclusión de nuestro recorrido sobre los fines de la historia en el siglo XXI. Como ya dijimos, desde la II Guerra Mundial se fueron acumulando instituciones y reglas de gobernanza (eufemismo de Gobierno Mundial) de forma más acelerada al calor de la globalización en el cambio de siglo. El reconocido fracaso de la gobernanza débil y fragmentada a la hora de implementar políticas eficaces a la altura de los retos presentes, no deja otra opción de futuro que un Gobierno Mundial de verdad. En lo que va de siglo XXI se ha alzado solicitándolo voces crecientes y plurales, con mayor intensidad desde 2008.

Existen precedentes históricos que lo vienen demandando desde el humanismo de Dante a la Ilustración de Rousseau y Kant, a fin de asegurar la paz, la seguridad y los derechos humanos en el mundo. En el siglo XIX Marx va más allá, predica una revolución mundial que, mediante un periodo transitorio de carácter estatal y por tanto mundial, conduzca a una sociedad sin clases. En el siglo XX, Einstein pide una

Cadernos do Tempo Presente, São Cristóvão-SE, v. 08, n. 04, p. 03-15, jul./dez. 2017| http://www.seer.ufs.br/index.php/tempo 
"autoridad política común para todos los países" que acabase con las guerras, valorando la idea naciente de los Estados Unidos de Europa, la Liga de Naciones y una ONU que le parecía insuficiente ${ }^{\mathrm{XIX}}$.

A partir de 1989, una serie de trabajos académicos y no académicos vuelven sobre el gran tema ${ }^{\mathrm{Xx}}$, una vez que desaparece la división del mundo en bloques irreconciliables. Talbot publica en 1992, "El nacimiento de la nación global"XXI, siguiendo a Garner que ya reivindicaba en 1974, al rebufo del movimiento del 68, una federación mundial construida desde abajo ${ }^{\mathrm{XXII}}$. Después, en pleno auge del movimiento antiglobalización, Falk y Strauss escriben en 2001, para la revista Foreign Affairs su artículo "Hacia un parlamento mundial"XXIII, argumentando que al igual que se hizo con el New Deal hoy era primordial un Gobierno Mundial para "salvar el capitalismo". En 2004, Jacques Attali profetizaba: "en 2050 habrá un Gobierno Mundial"XXIV . En 2005, Rajesh Tandon crea el Foro Democrático Mundial para promover una democracia mundial $^{\mathrm{XXV}}$.

La crisis del 2008 comporta un nuevo impulso a la iniciativa pro-Gobierno Mundial, desarrollada al margen de los políticos de todas las ideologías (ubicados más bien en la corta duración), con alguna excepción. En octubre de 2008, el ex-primer ministro Gordon Brown plantea la urgencia de crear una "autoridad financiera global"XXVI. En diciembre de 2008, Rachman ${ }^{\text {XXVII }}$ ex-miembro del Grupo Bilderberg, dice en Financial Times que: "por primera vez en mi vida, creo que la formación de una especie de gobierno mundial es posible", pone la Unión Europea como ejemplo XXVIII, reclama un Estado de Derecho Global y adelanta que el proceso será lento y doloroso. Cierto, lo está siendo.

El movimiento global de los indignados iniciado en 2011 supondrá otro punto de inflexión. Eduardo Punset, aplaude la rebelión de los indignados del $15 \mathrm{M}^{\mathrm{XXIX}}$ dos meses después de razonar las ventajas de un Gobierno Mundial ${ }^{\mathrm{XXX}}$. En julio de 2011, Joseph Deisss, Presidente de la Asamblea General de la ONU, asevera que "el movimiento de los indignados pone de relieve la necesidad de crear un gobierno económico mundial... representativo, eficaz y coherente"XXXI. En setiembre de 2011, ATTAC, el grupo más influyente del Foro Social Mundial (Porto Alegre), se plantea exigir un Gobierno

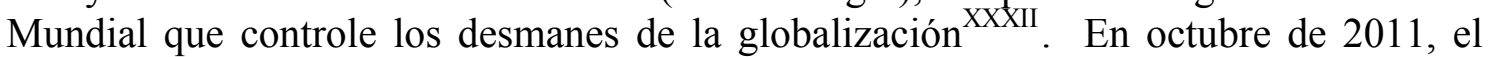
Consejo Pontificio de Justicia y Paz propone asimismo, influido sin duda por la rebelión juvenil global, un Gobierno Mundial y un único Banco Central ${ }^{\text {XXXIII }}$. En noviembre de 2011, será José Múgica, Presidente de la República del Uruguay, otro de los pocos (ex) políticos que se comprometen con la globalización política: urge una "Gobernanza mundial más equitativa y menos imperial" XXXIV .

En 2015, será Bill Gates quien proclame que la ONU ha fracasado y precisamos un Gobierno Mundial para solucionar los problemas globales de la pobreza, el hambre y el cambio climático ${ }^{\mathrm{XXV}}$. Finalmente, en 2017, Stephen Hawking afirma -un siglo después de Einstein- al The Times que hay que crear un Gobierno Mundial "para que el avance tecnológico no pueda destruir la especie humana", así como para enfrentarse al peligro de las guerras nucleares o biológicas XXXVI.

En resumen, un clamor diverso de voces complementarias de ideologías y países distintos que exigen más o menos lo mismo: un Gobierno Mundial elegido, junto con una Constitución y un Parlamento mundiales, que tengan por cometidos asegurar el control de los mercados y la nueva economía global y la salvaguardia de la paz, y apliquen políticas sociales y ambientales que rectifiquen de manera incluyente la

Cadernos do Tempo Presente, São Cristóvão-SE, v. 08, n. 04, p. 03-15, jul./dez. 2017| http://www.seer.ufs.br/index.php/tempo 
globalización. Obviamente, como sucede con los Gobiernos estatales, regionales y locales, los programas de los hipotéticos y sucesivos gobiernos de ámbito global estarán marcados por los resultados obtenidos en las periódicas elecciones mundiales, a partir de un proceso constituyente para el que se proponen diferentes vías: iniciativa de la ONU, federación de países, Gobierno provisional... Todo a la vez, seguramente.

Hemos tratado de escapar tanto de la escatología como de la utopía, y basarnos en los datos de la realidad inmediata, aportando enfoque histórico y nuestra propia interpretación, partidaria de culminar política e institucionalmente las demandas múltiples de intelectuales y ex-políticos en favor de un Gobierno Mundial. Pero ¿cuándo tendremos una autoridad pública mundial elegida por los ciudadanos que neutralice fines indeseables como el caos, el autoritarismo y el terrorismo? Cuando no quede más remedio: los perjuicios se hagan intolerables y las personas que lo exijan se multipliquen desbordando los Estados nacionales, que siguen siendo quienes malamente marcan el paso (con permiso de los mercados) como en los siglos XIX y XX.

Es habitual referenciar hacia la mitad del siglo, en el año-fetiche de 2050, las proyecciones y prospecciones relativas a los avances y problemas que ponen en peligro el planeta y la propia humanidad. Ese difícil de saber, porque los males que nos acechan son palpables, adelantan a mucha velocidad y la vieja gobernanza se hace día a día más insuficiente. Puede ser antes o después, lo que sería una desgracia para millones de personas. Dependerá y mucho de cuándo se generen procesos reales y potentes de cambio global de tipo social y político. De manera que los que nos han gobernado hasta ahora de manera deslavazada, en favor de unos pocos, sin que nadie les hubiese votado, no lo puedan seguir haciendo.

No son pocas las amenazas en gran parte inéditas que nos hacen temer lo peor, mientras sigan mandado más o menos ocultamente los poderes fácticos económicos transnacionales: la (s) nueva (s) crisis económica (s), que agravará (n) las desigualdades sociales y espaciales que está engendrando la globalización; el "fin del trabajo" a causa de la robotización; el incremento demográfico y la crisis alimentaria; el hambre, la pobreza y las epidemias; el calentamiento global y la crisis ecológica; el agotamiento de las energías fósiles; los desplazamientos masivos de población emigrante y refugiada; terrorismo global, nuevas guerras y amenazas nucleares. De seguir así, vamos hacia la hecatombe. No somos pesimistas por sistema, pero lo feo de la realidad no se puede infravalorar, hay millones de vidas en juego.

Lo estamos viendo: ningún gobierno nacional, grupos de gobiernos o alianza de grandes potencias, puede hacer frente a los desafíos globales y neutralizar (en el supuesto que quisieran) los fines de la historia más dañinos. Como tantas veces en la historia, la solución no vendrá pues del orden establecido, vendrá de un desarrollo mayúsculo de la comunidad global crítica que se está formando, dentro y fuera de las redes sociales, de movimientos sociales y ONGs, científicos y académicos, miembros de instituciones internacionales, empresas tecnológicas vinculadas a Internet, Iglesias, países y regiones perjudicados por esta globalización desigual, opciones políticas de nuevo o viejo cuño que entiendan el mundo que vivimos desde un óptica sensible al sufrimiento y los derechos de todos los seres humanos y del medio natural. Sólo una democracia más joven, participativa, real y global hará posible el gran cambio: que la historia nos acompañe. 


\title{
LOS FINES DE LA HISTORIA EN EL SIGLO XXI
}

\author{
CARLOS BARROS
}

\section{Notas}

I Versión escrita y ampliada de la conferencia de Carlos Barros en el III Foro Internacional "Rusia e Iberoamérica en el mundo globalizante: historia y perspectivas", Universidad Estatal de San Petersburgo, Rusia, 2-4 de octubre de 2017 (https://youtu.be/z7BHBPtFJ0c).

II Director-Fundador de la Red Académica Internacional Historia a Debate. Profesor de Historia Medieval e Historiografía de la Universidad de Santiago de Compostela. Más información en: www.cbarros.com y www.h-debate.com.

III Es evidente que no se cumplieron las profecías de Francis Fukuyama sobre el "fin de la historia": después de 1989, la historia continúa más allá del horizonte clásico de la democracia liberal y capitalista decimonónica basada en el Estado-nación; tampoco la meta materialista de la historia (surgida asimismo en el siglo XIX) de una sociedad sin clases, por medio de un transitorio y todopoderoso Estado socialista, se derrumbó con el Muro de Berlín, debemos reconocerlo.

IV Siempre con una óptica de progreso: defendiendo desde la historia un futuro de desarrollo sostenible y democrático, social y ambiental.

V Sobre la noción de Historia Inmediata, BARROS, Carlos, "La Historiografía y la Historia Inmediatas: la experiencia latina de Historia a Debate (1993-2006)", Hablemos de Historia. Cuestiones teóricas y metodológicas de la historia, Paraná, Universidad Nacional de Entre Ríos,, nº 6, 2010, pp. 251-258.

VI Tampoco el fin histórico del Gobierno Mundial, activo como veremos desde los años 90 en la práctica y la teoría en su versión light de "gobernanza mundial".

VII Manifiesto historiográfico de HaD, Santiago de Compostela, HaD, 2001 (www.hdebate.com/Spanish/manifiesto/manifiesto had.htm).

VIII En el principio de este nuevo siglo las revoluciones violentas parecen descartadas, así como las grandes guerras mundiales, si bien existen conflictos armados en Oriente Próximo y África del Norte que alimentan el autoritarismo y el terrorismo islámico.

IX Término nacido con la globalización fin de siglo que significa "arte o manera de gobernar", adaptado al presente a las intensas e inéditas relaciones internacionales con la finalidad de dotarlas de modos de gobierno posibilistas y fragmentados, de bajo perfil y escasas atribuciones; un sustituto, en suma, del término 'gobierno' que significa mucho más: "acción y efecto de gobernar", para lo que se ha necesitado hasta ahora del "poder ejecutivo de un Estado" nacional (DLE).

X En 2001 se constituyó en Porto Alegre, Brasil, como parte del movimiento altermundista, el Foro Social Mundial como contrapunto del Foro Económico de Davos, donde se manifiestan también -desde 2008- ideas reformistas ante el declive del neoliberalismo, el auge del proteccionismo y el miedo patente a las reacciones populares o populistas.

XI China propuso en el Foro de Davos de 2017, hace un año, el objetivo de una "comunidad de destino común para la humanidad" que no va más allá de lo que tenemos: Mercado Global (http://www.chinatoday.mx/pol/content/2017-09/30/content_747739.htm)

XII Historia global de los indignados (2011-2014), conferencia de Carlos Barros en la Escuela Nacional de Antropología e Historia. Ciudad de México, 29 de setiembre de 2014 (https://youtu.be/_nWXygiVR1Q).

XIII https://blogs.worldbank.org/opendata/es/informe-sobre-el-desarrollo-mundial-2017-gobernanza-ylas-leyes-en-graficos.

XIV Parte de lo que fue el Califato Omeya en los siglos VII-VIII, su máximo objetivo, que incluía AlAndalus (España y Portugal), Grecia, Turquía y la mitad norte de África.

XV Entrevista para la revista The Atlantic, Boston, 8 de setiembre de 2010 (https://www.theatlantic.com/international/archive/2010/09/fidel-cuban-model-doesnt-even-work-for-usanymore/62602)

XVI Se logró en cierta forma, justo es reconocerlo, en contraste con una realidad en sentido contrario en el resto de América Latina (exceptuando Cuba).

XVII Acaba de suceder en Ecuador, el proyecto bolivariano de Rafael Correa ha sido derrotado en el referéndum del 4 de febrero de 2018 y la Revolución Ciudadana pasa a encabezar la oposición con un $36 \%$ de apoyo electoral, que no es poco.

XVIII. "Global Trends 2025: A Transformed World", National Intelligence Council, USA, November 2008

Cadernos do Tempo Presente, São

Cristóvão-SE, v. 08 , n. 04 , p. 03-15, jul./dez.

http://www.seer.ufs.br/index.php/tempo 


\title{
LOS FINES DE LA HISTORIA EN EL SIGLO XXI
}

\author{
CARLOS BARROS
}

(https:/www.dni.gov/files/documents/Newsroom/Reports\%20and\%20Pubs/2025 Global Trends Final Report.pdf).

XIX EINSTEIN, Albert, Mis ideas y opiniones, Barcelona, Editorial Antoni Bosch, 2011, pp. 123-127, 133, 135, 139, 140, 145, 150, 163-164.

XX Véase: Andrew GAVIN, Gobierno Mundial en

https://guerradeconocimiento.wordpress.com/nwo/gobierno-mundial/.

XXI TALBOT, Strobe, "The Birth of the Global Nation”, Time, New York, no 29, July 20th, 1992, pp. 38-39.

XXII GARNER, Richard, "The Hard Road to World Order", Foreign Affairs, New York, April 1974, (https://www.foreignaffairs.com/articles/1974-04-01/hard-road-world-order).

XXIII FALK Richard and STRAUSS Andrew, "Toward Global Parliament”, Foreign Affairs, New York, January/February 2001 (https://www.foreignaffairs.com/articles/2001-01-01/toward-global-parliament).

XXIV ATTALI, Jacques, "En 2050 habrá un gobierno mundial", La Nación, Buenos Aires, 1 de diciembre de 2004 (http://www.lanacion.com.ar/658930-en-2050-habra-un-gobierno-mundial-asegurajacques-attali).

XXV http://world-governance.org/.

XXVI The Washington Post, Washington D. C., October 17, 2008 (http://www.washingtonpost.com/wpdyn/content/article/2008/10/16/AR2008101603179.html).

XXVII RACHMAN, Gideon, "And now for a world government", The Financial Times, London, December 8, 2008 (http://www.ft.com/cms/s/0/7a03e5b6-c541-11dd-b516-000077b07658.html).

XXVIII La experiencia europea demuestra que una unión puramente económica, no funciona -incluso puede retroceder- sin un gobierno elegido, un parlamento soberano y una política social unificada y avanzada.

XXIX Intervención el 25 de mayo de 2011 en la Acampada de Oviedo: https://www.youtube.com/watch?v=FYReCuj6ksM.

XXX “¿Qué ventajas tendría un gobierno único?”, XLSemanal, Madrid, 20 de marzo de 2011 (http://www.movimientarios.com/Punset\%20gobierno\%20mundial\%20semanal20110320.pdf).

XXXI DEISS, Joseph, "ONU: Se necesita un gobierno económico mundial" 4/7/2011 (http://www.un.org/spanish/News/story.asp?NewsID=21304\#.WmYUwa7iYnQ).

XXXII MERINO, Susana, "El gobierno mundial y el imperativo de la desmundialización", 23 de setiembre de 2011 (http://www.attacmadrid.org/?p=5564).

XXXIII Defiende el Vaticano un Gobierno Mundial que gestione el bien común (desarme integral, seguridad global, crisis alimentaria, regulación de la emigración), Libre Mercado 24/10/2011 (https://www.libremercado.com/2011-10-24/el-vaticano-pide-un-gobierno-mundial-y-un-unico-bancocentral-1276439243/); Benedicto XVI lo repite en un discurso el 3 de diciembre de 2012 donde propugna la "construcción de una comunidad mundial, con la autoridad correspondiente" para servir al "bien común de la familia humana" (http://www.catolicosalerta.com.ar/noticias03/nuevo-orden-mundial.html); en 2015 y 2017, el Papa Francisco añade a las tareas del futuro Gobierno Mundial: hacer frente a la crisis ambiental y el establecimiento de una justicia social global, "para salvar a la humanidad" (http://www.cristianosaldia.net/index.php/mundo-cristiano/papa-francisco-pide-un-nuevo-gobierno-

mundial-para-salvar-a-la-humanidad.html. https://alimentaycura.com/2017/07/09/el-papa-pide-ungobierno-mundial-para-salvar-la-humanidad/).

XXXIV Casa América Actualidad, Madrid, 8/11/2011 (http://www.casamerica.es/actualidad/mujicareclama-una-gobernanza-mundial-mas-equitativa-y-menos-imperial); cinco años después Múgica insiste en la exigencia de una gobernanza mundial que ponga en marcha un Plan Marshall contra la pobreza que resuelva en origen el problema de los refugiados, DW Actualidad, Berlín, 24/6/2016 (http://www.dw.com/es/jos\%C3\%A9-mujica-necesitamos-una-gobernanza-mundial/a-19351468).

XXXV GATES, Bill "Wir brauchen eine Weltregierung", Huffington Post, Madrid, 27/1/2015 (http://www.huffingtonpost.de/2015/01/27/bill-gates-wir-brauchen-eine-weltregierung_n_6556658.html). XXXVI World Economic Forum, Ginebra, 9/3/2017 (https:/www.weforum.org/es/agenda/2017/03/ungobierno-mundial-la-idea-de-stephen-hawking-para-que-el-avance-tecnologico-no-acabe-destruyendo-laespecie-humana).

Cadernos do Tempo Presente, São Cristóvão-SE, v. 08, n. 04, p. 03-15, jul./dez. 2017| http://www.seer.ufs.br/index.php/tempo 


\section{Referencias}

ATTALI, Jacques. En 2050 habrá un gobierno mundial. La Nación, Buenos Aires, 01 de diciembre de 2004.

BARROS, Carlos. La Historiografía y la Historia Inmediatas: la experiencia latina de Historia a Debate (1993-2006). Hablemos de Historia. Cuestiones teóricas y metodológicas de la historia. Paraná: Universidad Nacional de Entre Ríos, $n^{\circ}$ 6, 2010, pp. 251-258.

BASCHET, Jérôme. Manifiesto historiográfico de HaD. Historia a debate - HaD. Santiago de Compostela: 2001. Disponible en: www.h-debate.com/Spanish/ manifiesto/manifiestohad.htm.

BARROS, Carlos. Historia global de los indignados (2011-2014). In: Escuela Nacional de Antropología e Historia. Ciudad de México, 29 de setiembre de 2014. Disponible en: https://youtu.be/ nWXygiVR1Q.

DEISS, Joseph. ONU: Se necesita un gobierno económico mundial. Noticias ONU. 04 de Julio de 2011 Disponible en: http://www.un.org/spanish/News/story.asp?News ID=21304\#.WmYUwa7iYnQ.

EINSTEIN, Albert. Mis ideas y opiniones. Barcelona: Editorial Antoni Bosch, 2011.

FALK Richard; STRAUSS Andrew, "Toward Global Parliament". Foreign Affairs, New York: Enero/Febrero 2001. Disponible en: https://www.foreignaffairs.com/articles/2001-01-01/toward-global-parliament

GATES, Bill. Wir brauchen eine Weltregierung, Huffington Post. Madrid, 27 de enero de 2015. Disponible en: http://www.huffingtonpost.de/2015/01/27/bill-gates-wirbrauchen-eine-weltregierung n_6556658.html

GARNER, Richard, "The Hard Road to World Order". Foreign Affairs, New York: Abril 1974. Disponible en: https://www.foreignaffairs.com/articles/1974-04-01/hardroad-world-order.

GAVIN, Andrew. Gobierno Mundial. In: Guerra de conocimiento Alejada de la Naturaleza, la existencia humana queda vacía de contenido. Disponible en: https://guerradeconocimiento.wordpress.com/nwo/gobierno-mundial/.

Cadernos do Tempo Presente, São Cristóvão-SE, v. 08, n. 04, p. 03-15, jul./dez. 2017| http://www.seer.ufs.br/index.php/tempo 
MERINO, Susana. El gobierno mundial y el imperativo de la desmundialización. Attac Madrid - justicia económica global, 23 de setiembre de 2011. Disponible en: http://www.attacmadrid.org/?p=5564.

RACHMAN, Gideon. And now for a world government". The Financial Times. London, 08 de Diciembre de 2008. Disponible en: http://www.ft.com/cms/s/0/7 a03e5b6-c541-11dd-b516-000077b07658.html

TALBOT, Strobe. The Birth of the Global Nation. Time, New York, $n^{\circ} 29$, July 20th, 1992, pp. 38-39. 